\title{
Erratum to: Olfactory Cues From Pathogenic Fungus Affect the Direct of Motion of Termites, Coptotermes formosanus
}

\author{
Aya Yanagawa $^{1}$ - Tomoya Imai ${ }^{1}$ - Toshiharu Akino ${ }^{2}$ - Yoshihiro Toh ${ }^{3}$. \\ Tsuyoshi Yoshimura ${ }^{1}$
}

Published online: 13 September 2016

(C) Springer Science+Business Media New York 2016

Erratum to: J Chem Ecol (2015) 41:1118-1126

DOI 10.1007/s10886-015-0649-8

On page 1120, the unit associated with the external standard was mistyped. The solution of external standard was ' $10 \mathrm{ng} /$ $\mu \mathrm{l}$ ', not 'ng/ml'.

On page 1120 we should have reported that 'The GC injections were $1 \mu \mathrm{l}$ of sample or standard for these analyses'.

On page 1120 the standards used for $\mathrm{Y}$ tube tests are not adequately described. We should correct the current text as follows: 'Dilutions were made by carrying out a serial dilution of $1 \mu \mathrm{l} / \mathrm{ml}$ solutions for each compound of interest (for 3octanone, $1 \mu \mathrm{l} / \mathrm{ml}=8.2 \mathrm{mg} / \mathrm{ml}$; for 1-octene-3-ol, $1 \mu \mathrm{l}$ $/ \mathrm{ml}=8.4 \mathrm{mg} / \mathrm{ml})$. The solutions were diluted to concentrations as low as $8 \times 10^{-18} \mathrm{ng} / \mathrm{ml}$, which was the lower limit of detection of 3-octanone with our GC-MS method.'

On page 1122 the units were again mistyped. The correct concentration of 1 -octen-3-ol was $0.052 \pm 0.049 \mathrm{ng} / \mu \mathrm{l}$ in $10^{7}$ conidia, and 3-octanone was $0.044 \mathrm{ng} / \mu \mathrm{l}$ in $10^{7}$ conidia.

The online version of the original article can be found at http;//10.1007 /s10886-015-0649-8.

Aya Yanagawa

ayanagawa@ rish.kyoto-u.ac.jp

1 Research Institute for Sustainable Humanosphere, Kyoto University, Uji 611-0011, Japan

2 Laboratory of Applied Entomology, Kyoto Institute of Technology, Ukyo-ku, Kyoto 616-8354, Japan

3 Department of Biology, Faculty of Science, Kyushu University, Higashi-ku, Fukuoka 812-8581, Japan 